\title{
BABESIOSE CANINA: ASPECTOS HEMATOLÓGICOS E COMPARAÇÃO DE MÉTODOS DE DIAGNÓSTICO
}

\section{Canine Babesiosis: Hematological Aspects and Comparison of Diagnostic Methods}

\author{
Eloan Mendes Vieira ${ }^{1}$ \\ Júlia Rodrigues Ortega ${ }^{2}$ \\ Vanessa de Andrade Royo ${ }^{3}$ \\ Afrânio Farias de Melo Júnior ${ }^{4}$ \\ Dario Alves de Oliveira ${ }^{5}$ \\ Elytania Veiga Menezes ${ }^{6}$
}

Resumo: A babesiose canina é uma hemoparasitose causada por agentes etiológicos do gênero Babesia. A utilização do diagnóstico clínico é imprecisa devido a existência de sinais clínicos inespecíficos, e os exames usados rotineiramente como o esfregaço sanguíneo apresenta muitos resultados falso negativos. Objetivo comparação da eficiência do diagnóstico por padrões hematológicos, esfregaço sanguíneo, e por reação em cadeia da polimerase (PCR). Método trata-se de uma pesquisa realizada com de 80 cães que se encontravam sobre responsabilidade do Centro de Controle Zoonoses. Por meio da coleta de $3 \mathrm{ml}$ de sangue venoso, por animal para a realização dos

\footnotetext{
${ }^{1}$ Mestre em biotecnologia Universidade Estadual de Montes Claros (UNIMONTES). Montes Claros/MGBrasil. Doutorando da Universidade Federal de Ouro Preto (UFOP). Ouro Preto/MG. Brasil. $\square$ eloanmv@gmail.com. (1) https://orcid.org/0000-0002-2234-6999.

${ }^{2}$ Mestranda em Biotecnologia pela Universidade Estadual de Montes Claros (UNIMONTES). Montes Claros/MG- Brasil. $\square$ juliarortegar@gmail.com. (1) https://orcid.org/0000-0002-7100-1890.

${ }^{3}$ Doutora em produtos naturais sintéticos. Universidade de São Paulo, USP. Professor Departamento de Ciências Biológicas, Universidade Estadual de Montes Claros (UNIMONTES). Montes Claros/MG- Brasil. $\square$ vanroyo31@gmail.com. (I) https://orcid.org/0000-0002-4842-3569.

${ }^{4}$ Doutor em Engenharia Florestal. Universidade Federal de Lavras, Professor Departamento de Ciências Biológicas, Universidade Estadual de Montes Claros - UNIMONTES, Montes Claros MG- Brasil. $\square$ afraniofariasdemelo@gmail.com. (D) https://orcid.org/0000-0001-7899-3979.

${ }^{5}$ Doutor em Fitotecnia (Produção Vegetal) pela Universidade Federal de Viçosa, UFV, Brasil. Professor do Departamento de Ciências Biológicas da Universidade Estadual de Montes Claros - UNIMONTES, Montes Claros/MG. Brasil. $\square$ dario.aol@gmail.com. (1) https://orcid.org/0000-0002-8161-4607.

${ }^{6}$ Doutora em Ciências Biológicas (Biologia Genética). Universidade de São Paulo, USP, Brasil. Professor do Departamento de Ciências Biológicas da Universidade Estadual de Montes Claros - UNIMONTES, Montes Claros/MG - Brasil. $₫$ menezes.elytania@gmail.com. (1) https://orcid.org/0000-0003-2574-9360.
}

$\begin{array}{ccc}\text { Recebido em } & \text { Aceito em } & \text { Publicado em } \\ 27 / 04 / 2021 & 15 / 06 / 2021 & 18 / 06 / 2021\end{array}$


testes. Resultados, observou-se leve a moderada anemia nas 80 amostras analisadas, porém sem diferenças significativas nos parâmetros do hemograma dos cães positivos e negativos para a babesiose. Embora o diagnóstico pelo esfregaço sanguíneo tenha sido negativo, a PCR apresentou positividade de 46,2\% (37/80) para Babesia canis. Foi identificado alto índice de resultados positivos para Babesia canis nos cães parasitados pelo carrapato vetor. Considerações finais a partir dos resultados encontrados, conclui-se que existe fragilidade nos exames utilizados rotineiramente para o diagnóstico da babesiose canina quando comparado ao diagnóstico molecular. Evidenciando a necessidade de implantação de novas metodologias para diagnóstico mais eficiente.

Palavras- chave: 28S rDNA; Hemograma; Hemoparasitose; Babesiose; Diagnóstico Molecular.

Abstract: Canine babesiosis is a hemoparasitosis caused by etiological agents of the Babesia genus. The use of clinical diagnosis is imprecise due to the existence of unspecific clinical signs, and routinely used tests such as the blood smear have many false negative results. Objective comparison of diagnostic efficiency by hematological patterns, blood smear, and by polymerase chain reaction (PCR). Method this is a research carried out with 80 dogs that were under the responsibility of the Zoonoses Control Center. By collecting $3 \mathrm{ml}$ of venous blood per animal for testing. Results, there was mild to moderate anemia in the 80 samples analyzed, but without significant differences in the blood count parameters of dogs positive and negative for babesiosis. Although the diagnosis by blood smear was negative, PCR was 46.2\% (37/80) positive for Babesia canis. A high rate of positive results for Babesia canis was identified in dogs parasitized by the vector tick. Final considerations from the results found, it is concluded that there is weakness in the tests routinely used for the diagnosis of canine babesiosis when compared to molecular diagnosis. Evidencing the need to implement new methodologies for more efficient diagnosis.

Keywords: 28S rDNA; Blood Count; Hemoparasitosis; Babesiosis; Molecular diagnosis.

\section{INTRODUÇÃO}

Nas A babesiose é uma zoonose emergente causada por parasitas intraeritrocitários, protozoários do filo Apicomplexa da ordem Piroplasmida, do gênero Babesia ${ }^{1,2,3,4}$. O gênero possui mais de 100 espécies descritas infectantes de mamíferos e aves. E é considerada a segunda parasitose mais comum no sangue de mamíferos após os tripanossomatídeos ${ }^{1,2}$. Foram os primeiros hemoparasitas transmitidos por artrópodes a serem descritos como patógenos de vertebrados ${ }^{5}$. As 
espécies de Babesia são, no mundo, os principais patógenos transmitidos por carrapatos infectantes de glóbulos vermelhos de animais, sendo também, relatados casos em humanos ${ }^{6}$.

A babesiose é transmitida por carrapatos (Ixodidae) dos gêneros Rhipicephalus, Ixodes, Haemaphysalis e Hyalomma. Estes possuem papel essencial no ciclo de vida de Babesia spp., por atuarem como vetores, transmitindo o agente etiológico durante o repasto sanguíneo nos hospedeiros vertebrados. Que atuam como hospedeiros definitivos do agente etiológico ${ }^{1,3}$, local onde ocorre a fase sexual do ciclo de vida da Babesia spp 5 .

Um dos primeiros casos de babesiose humana relatado no Maine ocorreu em 2001, e outros casos de babesiose humana foram relatados associado à transfusão sanguínea em 2007. Autores como Smith em 2014, relataram casos de babesiose humana causados por B. microti, que se tornou ameaça à saúde pública. Estes casos ocorreram no nordeste e no meio-oeste dos Estados Unidos, onde foi relatada densas populações de carrapatos Ixodes scapularis e alta prevalência de Borrelia burgdorferi em carrapatos ${ }^{7}$.

Alguns estudos relatam também outras formas de transmissão ainda pouco estudadas ou conhecidas, como a transmissão transplacentária em cães, que tem sido investigada pelo surgimento de estudos que demostram alta parasitemia no sangue de cães neonatos, filhos de mães portadoras do parasita, que por serem recém-nascidos, ainda não teriam entrado em contado com o vetor transmissor, carrapato, como observado por Sobczyk, Agnieszka e colaboradores em $2005^{10}$.

Outro estudo relata a ocorrência de babesiose congênita em dois potros nascidos de éguas portadoras do parasita. Estas testaram positivas para Theileria equi e Babesia caballi por meio da visualização de formas intraeritrocíticas em esfregaços de sangue, e nas reações de Imunofluorescência indireta (RIFI) e nestedPCR. O sangue dos potros foi analisado logo após o nascimento e se apresentaram positivos na PCR para Theileria equi, enquanto que apenas um deles apresentou reação positiva para $B$. caballi. O estudo comprovou a ocorrência de babesiose congênita em potros recém-nascidos, no entanto, ainda são necessários estudos que permitam elucidar se a infecção ocorre por transmissão transplacentária ou no momento do parto ${ }^{11}$.

A babesiose canina é causada pelos agentes etiológicos Babesia canis, B. vogeli, B. rossi e B. gibsoni ${ }^{4,9}$. B. canis é transmitida pelo carrapato vetor Dermacentor reticularis na Europa. B. rossi é transmitida na África do Sul por Haemaphysalis leachi ${ }^{4}$. Já no Brasil, B. vogeli é a principal causadora da babesiose em cães, transmitida através do carrapato vermelho do cão, vetor Rhipicephalus sanguineus ${ }^{5}$ embora também já foram relatadas infecções causadas por B. gibsoni ${ }^{4}$. 
Embora a etiologia da doença seja variável conforme a espécie infectante, de forma geral, as infecções podem ser crônicas, sem sinais clínicos, geralmente assintomáticas ou com sintomas discretos; ou agudas, com sintomas mais evidentes ${ }^{5,8}$. O grau da infecção também pode variar de acordo com aspectos do hospedeiro, principalmente a idade, eficiência do sistema imunológico e se existe a ocorrência de mais infecções por outros patógenos naquele hospedeiro ${ }^{5}$.

O diagnóstico clínico da babesiose canina baseia-se na anamnese e em sinais clínicos. Caracterizados por sinais inespecíficos como: anemia hemolítica, hepatoesplenomegalia, diarreia, hipertermia, hemoglobinúria, icterícia, anorexia, depressão e vômito ${ }^{12}$. São infecções subclínicas na maioria dos cães adultos, porém cães jovens e filhotes com 3 a 4 meses de idade são altamente susceptíveis à quadros mais graves ou até mesmo a morte na ausência de tratamento adequado e em tempo ágil ${ }^{5,10}$. Contudo, o diagnóstico clínico é impreciso e dificultado, uma vez que existem várias doenças com sinais clínicos semelhantes que acometem os cães ${ }^{13}$.

Alguns autores têm estudado também as alterações hematológicas ocasionadas pela babesiose em diferentes animais, como visto em diferentes regiões do Brasil. Tem-se notado grande diversidade de alterações hematológicas decorrentes da babesiose canina, as alterações de maior frequência são: anemia normocítica normocrômica, policromasia, anisocitose, leucocitose por neutrofilia, monocitose, linfopenia e trombocitopenia ${ }^{21}$.

Os cães podem ser infectados por diversas subespécies de Babesia spp, ou, até mesmo coinfectados por outras infecções oportunistas, apresentando suscetibilidades diferentes aos medicamentos, podendo responder de maneira diferenciada aos tratamentos ${ }^{22}$. O tratamento desta infecção é realizado com o uso de vários medicamentos ou combinações dos mesmos. É importante tratar as infecções babesianas com os medicamentos anti-protozoários mais eficazes ou suas combinações, sendo necessário reconhecer as limitações do tratamento. Os medicamentos mais utilizados e estudados são Dipropionato de imidocarbe, Aceturato de diminazene, Azitromicina e Clindamicina. O mais utilizado atualmente para tratar infecções por B. vogeli em cães é o Dipropionato de imidocarbe, além de terapia e medicamentos de suporte, como fluido terapia e até mesmo transfusões sanguíneas dependendo do quadro clinico no qual o animal se encontra ${ }^{23}$.

No diagnóstico molecular, as ferramentas baseadas na Reação em Cadeia da Polimerase (PCR) representam uma ferramenta promissora para o diagnóstico de muitas doenças parasitárias ${ }^{14}$. A PCR possibilita a detecção e diagnóstico em infecções agudas, subclínicas ou crônicas mesmo nos casos de baixa parasitemia, além da diferenciação entre subespécies ${ }^{15,16,17}$. Quando comparada com os testes rápidos atualmente utilizados, como o esfregaço sanguíneo, a PCR pode ser utilizada na 
detecção de fragmentos de DNA e ou RNA de Babesia $s p^{18}$, sendo uma técnica sensível e específica, permitindo maior rapidez e confiabilidade nos resultados além da diferenciação das subespécies ${ }^{4,14}$. Enquanto os testes rápidos podem oferecer resultados não confiáveis, de caráter duvidoso, podendo ocorrer reações cruzadas com outros tipos de parasitos. Além de não conseguir diferenciar as subespécies causadoras da infecção ou gerar resultados falso-positivo ou falso-negativos devido a variação da parasitemia ${ }^{19,20}$.

A atenção para a situação epidemiológica é necessária. Ou seja, é importante o estudo da estabilidade ou instabilidade endêmica em determinada região com a finalidade de mensurar a probabilidade de ocorrência de surtos de importância medico veterinária. Como também estudos diagnósticos mais eficientes para fornecer resultados mais precisos, rápidos e confiáveis afim de agilizar o início do tratamento direcionado e de forma mais eficaz. Visando promover a recuperação mais rápida da saúde e bem estar do animal. Objetivou-se neste estudo, comparar a eficiência do diagnostico por padrões hematológicos e esfregaço sanguíneo, teste mais utilizado no diagnóstico, em relação a técnica de PCR, conhecida por apresentar alta eficiência e especificidade para o diagnóstico da babesiose canina.

\section{MÉTODOS}

$\mathrm{O}$ presente trabalho seguiu os preceitos nacionais e internacionais que regem o desenvolvimento de pesquisas em experimentação animal, e foi aprovado pela Comissão de Ética em Experimentação e Bem-Estar Animal (CEEBEA: no 116/2016) da Universidade Estadual de Montes Claros (UNIMONTES).

Neste estudo foram utilizadas 80 amostras de sangue venoso proveniente de cães de raça, porte, sexo e idade aleatórios, que apresentaram resultados positivos para leishmaniose visceral canina confirmada por teste rápido e Elisa pelo Centro de Controle Zoonoses (CCZ) da cidade de Montes Claros- MG. Os mesmos também apresentavam sintomas indicativos de infecções, como emagrecimento, feridas pelo corpo, apatia dentre outros, sem ter sido possível estimar a quanto tempo os mesmos se encontravam com esses sintomas devido a grande maioria ser cães de rua. Foram coletados $3 \mathrm{ml}$ de sangue venoso obtidos através da punção de uma veia braquial com auxílio de uma seringa descartável. As amostras foram colocadas em tubos contendo ácido etilenodiamino tetraacético (EDTA) um anticoagulante usado para manter a integridade das amostras como proposto por Moraes e colaboradores ${ }^{4}$. 
Uma alíquota de cada amostra de sangue foi encaminhada para o LABONORTE Laboratório de Patologia Clínica Animal, onde foi realizado o hemograma e leucograma através de contagem celular automatizada e microscopia - bc 2800. Também foi confeccionado o esfregaço sanguíneo por extensão que utilizou 5 uL de sangue fresco. Este foi corado com Giemsa para a observação dos merozoítos intraeritrocitários através do microscópio óptico, testes realizados pelo laboratório.

Outra alíquota de cada amostra de sangue venoso foi levada ao laboratório de Bioprospecção e Recursos Genéticos da UNIMONTES e estocadas a $-20^{\circ} \mathrm{C}$. Posteriormente foram submetidas à extração de DNA total através do método de Fenol-Clorofórmio ${ }^{24}$, com algumas adaptações. Para extração de DNA total foi utilizado $300 \mu \mathrm{L}$ de sangue total onde foram colocados em microtubos $2 \mathrm{ml}$ e adicionado $300 \mu \mathrm{L}$ de Tampão de lise celular (10 ml Tris-HCl 1M (pH 8,0), 8 ml EDTA 0,5 M (pH 8,0), $20 \mathrm{ml} \mathrm{NaCl} 5 \mathrm{M}$ e $2 \mathrm{ml}$ de SDS 10\%) e $5 \mu \mathrm{L}$ de proteinase $\mathrm{K}$ (200 $\mathrm{mg} / \mathrm{ml}$ ). As amostras foram incubadas em banho-maria a $65{ }^{\circ} \mathrm{C}$ por 2 horas, após verificada a lise completa da amostra, as proteínas foram precipitadas com $300 \mu \mathrm{L}$ de solução de Fenol: Clorofórmio: Álcool Isoamílico (25:24:1) respectivamente, e centrifugadas por 10 minutos a $12.000 \mathrm{rpm}$. O sobrenadante contendo o DNA foi coletado e transferido para novos microtubos de $2 \mathrm{ml}$ previamente identificados, precipitado com $300 \mu \mathrm{L}$ de solução Clorofórmio: Álcool (24:1) e centrifugado por 10 minutos a $12.000 \mathrm{rpm}$. O sobrenadante foi novamente coletado e transferido para novos microtubos de $1,5 \mathrm{ml}$ previamente identificados, adicionado $300 \mu \mathrm{L}$ de isopropanol para a precipitação do pellet de DNA. Quando não observada a formação do pellet, a amostra foi incubada por uma hora a $-20{ }^{\circ} \mathrm{C} \mathrm{e}$ posteriormente centrifugada por 10 minutos a $12.000 \mathrm{rpm}$. O sobrenadante foi descartado por inversão do tubo e o pellet de DNA foi lavado com $300 \mu \mathrm{L}$ de álcool absoluto, centrifugado por 10 minutos $12000 \mathrm{rpm}$. Foi descartado novamente o sobrenadante e realizada uma nova lavagem do pellet com $300 \mu \mathrm{L}$ de Álcool 70\%, centrifugado por $10 \mathrm{~min}$ a $12000 \mathrm{rpm}$. Foi desprezado todo o sobrenadante e os tubos foram secos através do repouso por no mínimo 1 hora. Após a secagem, o pellet de DNA foi suspendido em $50 \mu \mathrm{L}$ de tampão TE (10 mM Tris pH 8,0 e 1 mM EDTA) e aquecido em banho-maria a $65^{\circ} \mathrm{C}$ por uma hora. Em seguida o DNA foi estocado no freezer a $-20{ }^{\circ} \mathrm{C}$. A qualidade do DNA total foi verificada por eletroforese em gel de agarose a $1 \%$ corado com brometo de etidío.

O diagnóstico molecular foi baseado no protocolo de PCR proposto por Moraes e colaboradores em $2014^{4}$, envolvendo a amplificação de um fragmento do gene 28S rDNA de Babesia canis. Os primes utilizados na reação de PCR para a confirmação do gênero Babesia foram foward Bab-f 5'AAG TAC AAG CTT TTT ACG GTG 3', descrito por Martin ${ }^{25}$ e reverse Babesia common 5' 
CCT GTA TTG TTA TTT CTT GTC ACT ACC TC 3' descrito por Kordick ${ }^{26}$ que juntos geram um fragmento de 394 pares de bases.

As reações consistiram de um volume total de $25 \mu \mathrm{L}$, contendo $50 \mu \mathrm{g}$ de DNA total, $1 \mathrm{x}$ Tampão B tris-potássio $\mathrm{MgCl}_{2}$ 1,5mM kapa, $0,5 \mathrm{mM} \mathrm{MgCl}_{2}$ kapa, $10 \mu \mathrm{M}$ de cada primer, $3 \mathrm{mM}$ dos DNTPS Invitrogem e 1U de Taq DNA polimerase Kapa. A reação foi realizada em termociclador TC PLUS Techne Analítica, que consistiu em um ciclo de desnaturação inicial de 5 minutos a $94^{\circ} \mathrm{C}, 35$ ciclos de 1 minuto a $94{ }^{\circ} \mathrm{C}, 2$ minutos a $50{ }^{\circ} \mathrm{C}$, e 1 minuto a $72{ }^{\circ} \mathrm{C}$, precedida por uma extensão final de 5 minutos a $72^{\circ} \mathrm{C}$, como descrito em Moraes ${ }^{4}$ com algumas adaptações para este trabalho. $\mathrm{O}$ controle positivo utilizado foi referente a uma amostra DNA extraído a partir de amostra de sangue canino com confirmação da presença do parasita pelo esfregaço sanguíneo, doada pelo Laboratório de Virologia e Rickettsioses do Hospital Veterinário da Faculdade de Medicina Veterinária Universidade Federal de Mato Grosso (UFMT). Os controles negativos consistiam de todos os reagentes da PCR com substituição das amostras DNA por água destilada autoclavada. O produto da reação foi submetido à eletroforese em gel de agarose a 1,5\% contendo brometo de etidio. Foi utilizado o marcador de peso molecular LowRanger 100bp DNA Ladder (100bp-2000pb). A migração foi observada e fotografado no Fotoducumentador Nova Analítica transiluminado UV Gel Logic para a visualização das bandas amplificadas e as imagens foram armazenadas para posteriores analises.

A análise estatística foi realizada através do software Minitab 16 for Windows. O Teste T, realizado a 95\% intervalo de confiança, foi empregado para análise da associação entre animais positivos e negativos na PCR, identificando a relação PCR e hemograma. Teste de Mann- Whitney, a 5\% de significância $(\mathrm{p}<0,05)$, foi utilizado para identificar diferenças estatísticas entres as variáveis, sendo que os valores seguidos de mesma letra, na mesma coluna, não diferem significativamente. Também foi realizada a mediana da relação dos resultados da PCR com as variáveis, sexo, idade, raça, e presença de ectoparasitas.

\section{RESULTADOS}

$\mathrm{Na}$ análise dos esfregaços sanguíneos por extensão não foi observada a presença de merozoítos intraeritrocitários de Babesia spp nas amostras analisadas pelo laboratório. Os resultados obtidos pela análise de PCR apresentaram 46,25\% (37/80), de cães positivos para a espécie B. canis, através dos primers Bab-f e Babesia common com 394pb como representado na (Figura 1) e expressos na (Tabela 1). E 53,75\% (43/80), de negativos para Babesia spp. Em relação às metodologias testadas para o diagnóstico da patologia, a PCR se mostrou bem mais eficaz que o esfregaço sanguíneo, 
demostrando assim a fragilidade no diagnóstico pelo método atualmente mais utilizado pelos laboratórios de análises clinicas animal.

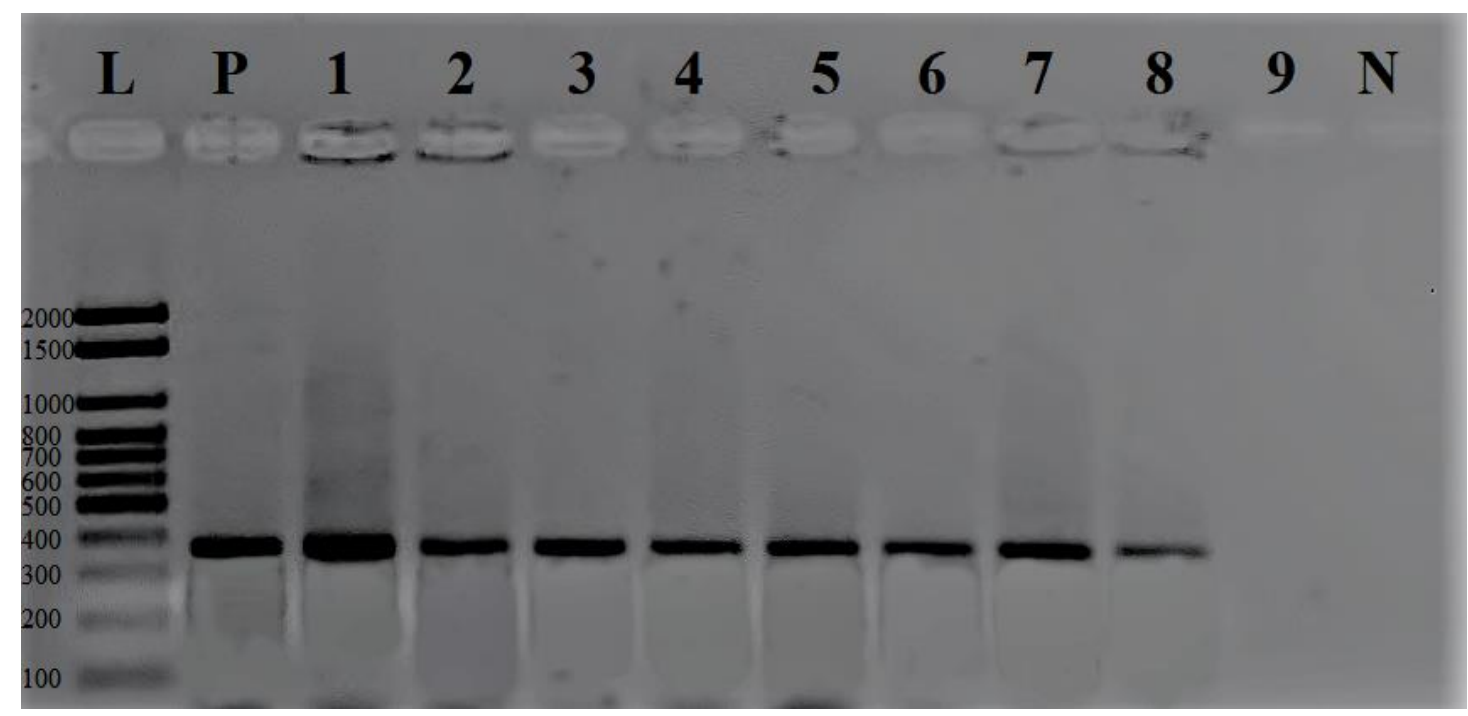

Figura 1. Detecção de B. canis através da PCR com os primers Bab-f e Babesia common, L= Padrão Ladder, 394pb indica padrão positivo para B. canis, $\mathrm{P}=$ Controle positivo, 1 ao 8 são amostras positivas para Babesia canis, 9 amostras negativa, $\mathrm{N}=$ Controle negativo.

Após as análises de hemograma, observou-se que os cães positivos $(\mathrm{n}=37)$ e negativos ( $\mathrm{n}=43$ ), para B. canis apresentaram valores de hemácias, hemoglobina e hematócrito bem semelhante, sendo notado um quadro de anemia leve em ambos os resultados, com valores médios pouco abaixo dos valores de referência como expresso na (Tabela 1). Isto foi confirmado ao observar os valores médios de hemácia, hemoglobina e hematócrito dos parâmetros citados acima, que resultaram em um p>0,05, (probabilidade de significância).

Em relação aos valores do leucograma, também não se observou diferença significativa ( $>0,05)$ entre os cães positivos e negativos na PCR quanto à média de leucócitos, bastonetes, segmentados, neutrófilos totais, eosinófilos, linfócitos, e monócitos sendo que os mesmos se encontraram dentro da faixa dos valores de referência (Tabela 1). Os resultados relacionados as plaquetas, tanto os animais positivos, quanto os negativos apresentaram valores normais comparados ao valor de referência, e não apresentaram diferenças significativas $(p>0,05)$. 
Table 1 Parâmetros do hemograma e leucograma assosiados a PCR para B. canis

\begin{tabular}{|c|c|c|c|c|c|c|c|}
\hline Parâmetros & $\begin{array}{c}\text { Resultado } \\
\text { de PCR }\end{array}$ & $\mathbf{N}$ & $\begin{array}{l}\text { Valor } \\
\text { médio }\end{array}$ & DP & EP & $\mathrm{p}$ & $\begin{array}{l}\text { Valores de } \\
\text { referência }\end{array}$ \\
\hline \multirow[b]{2}{*}{ Hemácias milh/mm³ } & Positivo & 37 & $4,64 c$ & 1,32 & 0,22 & \multirow[b]{2}{*}{0,796} & \multirow[b]{2}{*}{5,50 a 8,50} \\
\hline & & 43 & $4,72 \mathrm{c}$ & 1,36 & 0,21 & & \\
\hline \multirow{3}{*}{ Hemoglobina g/Dl } & Positivo & 37 & $10,20 \mathrm{c}$ & 3,1 & 0,51 & \multirow{3}{*}{0,984} & \multirow{3}{*}{12 a 18} \\
\hline & & & & & & & \\
\hline & Negativo & 43 & $10,19 \mathrm{c}$ & 3,1 & 0,47 & & \\
\hline \multirow[b]{2}{*}{ Hematócritos \% } & Positivo & 37 & $34,13 \mathrm{c}$ & 9,94 & 1,6 & \multirow[b]{2}{*}{0,946} & \multirow[b]{2}{*}{37 a 55} \\
\hline & Negativo & 43 & $33,98 \mathrm{c}$ & 9,85 & 1,5 & & \\
\hline \multirow{2}{*}{ Leucócitos /mm3 } & Positivo & 37 & $15473 b$ & 19779 & 3252 & \multirow{2}{*}{0,168} & \multirow{2}{*}{6000 a 17000} \\
\hline & Negativo & 43 & $10712 b c$ & 6335 & 966 & & \\
\hline \multirow[b]{2}{*}{ Bastonetes \% } & Positivo & 37 & $0,757 \mathrm{c}$ & 0,955 & 0,16 & \multirow[b]{2}{*}{0,906} & \multirow[b]{2}{*}{0 a 3} \\
\hline & Negativo & 43 & $0,79 \mathrm{c}$ & 1,58 & 0,24 & & \\
\hline \multirow{2}{*}{ Segmentados \% } & Positivo & 37 & $65,95 \mathrm{c}$ & 8,7 & 1,4 & \multirow[b]{2}{*}{0,502} & \multirow[b]{2}{*}{60 a 77} \\
\hline & Negativo & 43 & $67,26 \mathrm{c}$ & 8,62 & 1,3 & & \\
\hline \multirow{2}{*}{ Neutrófilos. Totais \% } & Positivo & 37 & $66,70 \mathrm{c}$ & 9,2 & 1,5 & \multirow{2}{*}{0,508} & \multirow{2}{*}{60 a 80} \\
\hline & Negativo & 43 & $68,07 \mathrm{c}$ & 9,14 & 1,4 & & \\
\hline \multirow[b]{2}{*}{ Eosinófilos \% } & Positivo & 37 & $3,43 \mathrm{c}$ & 2,29 & 0,38 & \multirow[b]{2}{*}{0,25} & \multirow[b]{2}{*}{2 a 12} \\
\hline & Negativo & 43 & $2,86 \mathrm{c}$ & 2,09 & 0,32 & & \\
\hline \multirow[b]{2}{*}{ Linfócitos \% } & Positivo & 37 & $27,6 \mathrm{c}$ & 12,6 & 2,1 & \multirow[b]{2}{*}{0,276} & \multirow[b]{2}{*}{12 a 30} \\
\hline & Negativo & 43 & $24,91 \mathrm{c}$ & 8,27 & 1,3 & & \\
\hline \multirow{2}{*}{ Monócitos \% } & Positivo & 37 & $4,22 \mathrm{c}$ & 1,87 & 0,31 & \multirow{2}{*}{0,9} & \multirow{2}{*}{3 a 10} \\
\hline & Negativo & 43 & $4,16 \mathrm{c}$ & 1,91 & 0,29 & & \\
\hline \multirow[b]{2}{*}{ Plaquetas /mm3 } & Positivo & 37 & $168919^{a}$ & 122384 & 20120 & \multirow[b]{2}{*}{0,728} & \multirow[b]{2}{*}{150000 a 900000} \\
\hline & Negativo & 43 & $159907^{\mathrm{a}}$ & 105778 & 16131 & & \\
\hline
\end{tabular}

Tabela 1. Teste T realizado a 95\% intervalo de confiança, N: número de cães, (a) Valores seguidos de mesma letra, na mesma coluna, não diferem significativamente através do teste de Mann- Whitney a 5\% de significância $(\mathrm{p}<0,05)$. DP: desvio padrão, EP: erro padrão, Valores de referência: de acordo com o laboratório LABONORTE. 
Levando em conta a relação dos cães positivos na PCR e as variáveis, sexo, idade, porte e raça, não foram encontrados resultados significantes, dados não mostrados. Podendo estar relacionados às variações da amostragem. Em relação à presença de ectoparasitas carrapatos, nos 80 cães analisados, foi obtido um total de 63 amostras positivas para a presença do carrapato no cão com $57,1 \%$ dos cães apresentaram-se positivos na PCR para B. canis, e nos cães com ausência de carrapatos apenas $5,88 \%$ foram positivos. Ou seja, a maioria dos animas portadores de carrapatos foram diagnosticados positivos para Babesia canis através da PCR.

\section{DISCUSSÃO}

A ausência de merozoítos intraeritrocitários de Babesia sp. é similar ao encontrado em estudos com esfregaços sanguíneo, que obtiveram baixa positividade para Babesia sp. Silva e colaboradores $^{27}$, observaram $1,4 \%$ de positividade em 146 cães analisados, Miranda ${ }^{28}$ observaram $1,47 \%$ de positivos para Babesia sp. através do esfregaço dos 2.031 cães analisados. Estes resultados diferem do trabalho de Laha ${ }^{9}$ que encontraram um total de 39,63\% de positivos para Babesia sp. no esfregaço sanguíneo em 111 cães analisados na qual também foram utilizados no estudo cães que apresentavam as mesmas variáveis de amostragem dos utilizados para a realização deste trabalho com exceção da positividade para a leishmaniose visceral canina. O esfregaço sanguíneo é uma técnica altamente específica, porém apresenta baixa sensibilidade, pois a parasitemia é variável, levando em conta o tempo de infecção, além das condições de saúde do animal, como alimentação cuidados de higiene, moradia adequada e cuidados médicos que podem influenciar diretamente no sistema imune dos mesmos, favorecendo assim uma menor multiplicação dos parasitas e surgimento de sintomas, visto também que não foi possível confirma a fase da infecção a qual os animais se encontravam devido a grade maioria serem cães de rua, podendo assim inferir que os mesmo já se encontravam em fase crônica da infecção, a qual tende a ter uma diminuição da parasitemia dificultando a observação de eritrócitos parasitados por merozoítos ${ }^{29}$, além disso, amostra utilizada possuía quantidade pequena de sangue o que pode influenciar diretamente no resultado, considerando que o animal esteja com baixa parasitemia ${ }^{30}$. Devemos considerar também a limitação da capacidade do operador em realizar o teste, visto que esse tipo de teste depende da capacitação, experiência e atenção extrema do mesmo, além de múltiplas variáveis como qualidade da coleta das amostras, preparo e coloração das lâminas.

Os resultados da análise de PCR se assemelham aos de Laha e colaboradores ${ }^{9}$ que encontraram um total de $56,75 \%$ de cães positivos para $B$. canis com a utilização dos primers PiroA e PiroB em 111 animais analisados. Já os resultados descritos por Moraes ${ }^{4}$, encontraram $22 \%$ de cães positivos em 100 cães analisados, usando os mesmos primers deste estudo, com associação de outros 


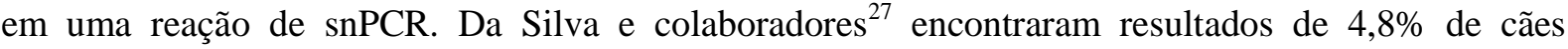
positivos para $B$. canis vogeli nos 146 cães analisados, com a utilização de diferentes primers, em Silva $^{31}$ observaram um total de $3,33 \%$ de positivos para B. canis vogeli nos 300 cães analisados. Martin ${ }^{25}$ realizou análise no Basic Local Alignment Search Tool (BLAST) em que demonstrou a alta especificidade do primer Bab-f para gênero Babesia e também notou $100 \%$ de especificidade e sensibilidade com os resultados que foram reproduzíveis em experimentos posteriores, comprovando assim a eficiência e especificidade dos primes usados neste estudo.

Essa divergência entre os resultados pode ser atribuída à quantidade amostral e as condições dos locais de coleta. Como no CCZ da cidade de Montes Claros, os cães ficam aglomerados em poucos recintos, ficam sujeitos a infecção no próprio local devido à grande quantidade de animais parasitados por carrapatos ali presentes. Associado a incerteza da origem dos animais analisados, como os cães de rua por exemplo, que possuem maior probabilidade de contrair infecções parasitárias devido à grande exposição aos vetores. Sem contar com a deficiência na alimentação e baixa qualidade de vida dos mesmos que pode influenciar diretamente o seu sistema imunológico, favorecendo assim outras infeções. Ao contrário dos cães domésticos que vivem com melhor qualidade de vida, além de estarem menos expostos ao carrapato vetor e possuírem assistência medica veterinária.

Os resultados do hemograma se assemelham aos de Furlanello ${ }^{32}$, que mostraram a ocorrência de anemia, de leve à moderada, em infecções causadas por B. canis, levando em conta que a replicação do parasita causa o rompimento das células vermelhas. Os resultados semelhantes podem ser explicados também pela presença de outros parasitas nos animais analisados, já que os animais deste estudo eram confirmados com leishmaniose visceral canina dentre outas patologias (dados fornecidos pelo CCZ e não mostrados). Alguns autores relatam a presença de anemia em cães infectados com B. canis, sem analisar a presença de outros hemoparasitas ${ }^{13,25}$.

Os resultados do leucograma contradizem com achados de Hagiwara ${ }^{33}$, que estudaram cães propositalmente infectados com B. canis e relataram leucopenia e neutropenia, associada às fases iniciais da infecção. Furlanello ${ }^{32}$ relata leucopenia em aproximadamente $69,5 \%$ dos cães infectados. O que pode ser explicado devido a própria infecção experimental, na qual pode se ter utilizar uma quantidade de inoculo bem superior à infeção realizada naturalmente pelo próprio carrapato vetor, o que desencadearia uma multiplicação mais elevada do agente causador da infecção, induzindo assim uma resposta imune desacerbada e consequentemente alterações no leucograma além do período da infecção, visto que no trabalho apresentado a infecção se encontrava em fase aguda, e os animais usados neste estudo eram de fase indeterminada o que pode ter influenciado diretamente nos 
resultados citados. Já o resultado dos eosinófilos se assemelha ao relatado por Zygner ${ }^{34}$ que não notaram alterações significativas no número de eosinófilos em cães infectados.

Os resultados referentes as plaquetas diferem das afirmações de Guimarães ${ }^{35}$ e Furlanello ${ }^{32}$, que notaram à ocorrência da diminuição do número de plaquetas em cães positivos. Os resultados observados neste trabalho podem estar relacionados a infecções tardias ou crônicas, que costumam manter valores normais no leucograma como descrito por Guelfi ${ }^{36}$, também podendo está relacionado a quantidade de plaquetas, devido aos diferentes estágios da patologia.

Comparando os resultados da presença de ectoparasitas o carrapato vetor, Da Silva ${ }^{27}$ analisando 146 cães encontraram um total de $8,6 \%$ de positivos nos 81 cães que mantinha a presença do carrapato vetor, e aqueles cães onde os vetores eram ausente, o resultado da PCR foi negativo. Podemos inferir que a maioria dos resultados positivos para B. canis podem estar ligados diretamente a presença do carrapato vetor, responsável pela principal forma de transmissão conhecida da parasitose, Para uma melhor analise e entendimento da transmissão vetorial, julgo necessário também a análise de PCR nos carrapatos encontrados nos cães, pois este tipos de analises esclareceria se a transmissão está ocorrendo de forma vetorial ou mesmo de outras formas como a transplacentária como visto anteriormente.

\section{CONCLUSÃO}

O presente estudo demonstrou que a PCR é uma ferramenta diagnóstica muito mais sensível do que o esfregaço sanguíneo, demonstrando as limitações e fragilidade do método mais utilizado atualmente pelos laboratórios. Os resultados do hemograma não revelaram diferenças significativas entre os cães positivos e negativos para B. canis. Esse resultado pode ser explicado devido a fase da infecção a qual os cães se encontravam e pela probabilidade de os cães serem portadores de outras patologias, como a leishmaniose visceral canina a qual já era confirmada, o que pode ter influenciado nestes resultados. É evidente também a necessidade de novas pesquisas abordando separadamente as infecções experimentais e naturais, além de incluir as condições no qual os cães se encontravam como a fase da infecção, além incluir analises de PCR no carrapatos encontrados no cães o que nos forneceria resultados mais precisos quanto as formas de transmissão. Os resultados deste estudo evidenciam a necessidade de políticas públicas de promoção da saúde e do bem-estar animal, bem como a implantação de laboratórios equipados e treinados para diagnóstico molecular e outras metodologias ou mesmo a utilização de pelo menos dois testes diferentes para diagnóstico, visto que os métodos moleculares como a PCR permitirá um melhor controle de cura dos cães tratados, por apresentar maior sensibilidade as demais métodos. 


\section{AGRADECIMENTOS}

Ao Laboratório de Bioprospecção e Recursos Genéticos, ao Programa de Pós-Graduação em Biotecnologia da Universidade Estadual de Montes Claros UNIMONTES pela oportunidade e incentivo na realização deste trabalho, ao Laboratório de Virologia e Rickettsioses do Hospital Veterinário da Faculdade de Medicina Veterinária Universidade Federal de Mato Grosso (UFMT) por ceder amostras positivas para a padronização e realização deste dos experimentos, ao centro de Controle e Zoonoses juntamente com a Secretaria de Saúde de Montes Claros, a qual através de um parceria possibilitou a obtenção das amostras utilizadas neste estudo, e Fundação de Amparo à Pesquisa do Estado de Minas Gerais FAPEMG pelo financiamento e apoio no projeto.

\section{REFERÊNCIAS}

1. ANTUNES, Sandra et al. Deciphering Babesia-vector interactions. Front. Cell. Infect. Microbiol, v. 7, p. 429, 2017. https://doi.org/10.3389/fcimb.2017.00429. Access en: 14 jun.2019.

2. ORKUN, Ömer; KARAER, Zafer. Molecular characterization of Babesia species in wild animals and their ticks in Turkey. Infect Genet Evol, v. 55, p. 8-13, 2017. https://doi.org/10.1016/j.meegid.2017.08.026. Access en:14 jun.2021.

3. JALOVECKA, Marie et al. Babesia life cycle-when phylogeny meets biology. Trends Parasitol, v. 35, n. 5, p. 356-368, 2019. https://doi.org/10.1016/j.pt.2019.01.007. Access en:9 jun.2021.

4. MORAES, Pablo Henrique Gonçalves et al. Optimization of a molecular method for the diagnosis of canine babesiosis. Rev Bras Parasitol vet, v. 23, n. 1, p. 105-108, 2014. https://doi.org/10.1590/S1984-29612014017. Access en:10 jun.2020.

5. SCHNITTGER, Leonhard et al. Babesia: a world emerging. Infect Genet Evol, v. 12, n. 8, p. 1788-1809, 2012. https://doi.org/10.1016/j.meegid.2012.07.004. Access en: 27 jan.2020.

6. CASATI, Simona et al. Presence of potentially pathogenic Babesia sp. for human in Ixodes ricinus in Switzerland. Ann Agric Environ Med, v. 13, n. 1, p. 65, 2006. Access en: 23 set.2019.

7. SMITH JR, Robert P., et al. Human babesiosis, Maine, USA, 1995-2011. Emerg. Infect. Dis, 20.10: 1727. 2014. https://doi.org/10.3201/eid2010.130938. Access en: 23 set.2019 
8. OTGONSUREN, Davaajav et al. Molecular epidemiological survey of Babesia bovis, Babesia bigemina, and Babesia sp. Mymensingh infections in Mongolian cattle. Parasitol. Int, v. 77, p. 102107, 2020. https://doi.org/10.1016/j.parint.2020.102107. Access en:12 set.2018

9. LAHA, R. et al. Babesia infection in naturally exposed pet dogs from a north-eastern state (Assam) of India: detection by microscopy and polymerase chain reaction. $J$ Parasit Dis, v. 38, n. 4, p. 389-393, 2014. https://doi.org/10.1007 / s12639-013-02611. Access en:5 ago.2019

10. SOBCZYK, AGNIESZKA S. et al. Usefulness of touchdown PCR assay for the diagnosis of atypical cases of Babesia canis canis infections in dogs. Bull Vet Inst Pulawy, v. 49, n. 4, p. 407, 2005. Access en: 17 mar. 2017.

11. SANTOS, T. M., Santos, H. A., \& Massard, C. L. Diagnóstico molecular de babesiose congênita em potros neonatos no estado do Rio de Janeiro, Brasil. Rev Bras Parasitol Vet 17(1), 348-350. 2008. Access en: 15 ago. 2017.

12. ALMOSNY, Nádia RP et al. Hemoparasitoses em pequenos animais domésticos e como zoonoses. Rio de Janeiro: NDL. F. Livros, 2002. Access en: 30 abr. 2017.

13. ABDULLAHI, S. U. et al. Clinical and haematological findings in 70 naturally occurring cases of canine babesiosis. J Small Anim Pract, v. 31, n. 3, p. 145-147, 1990. https://doi.org/10.1111/j.1748-5827.1990.tb00750.x. Access en: 13 set. 2017.

14. GASSER, Robin B. Molecular tools - advances, opportunities and prospects. Vet. Parasitol. v. 136, n. 2, p. 69-89, 2006. https://doi.org/10.1016/j.vetpar.2005.12.002. Access en: 22 ago. 2017.

15. CARRET, CÉLINE et al. Babesia canis canis, Babesia canis vogeli, Babesia canis rossi: differentiation of the three subspecies by a restriction fragment length polymorphism analysis on amplified small subunit ribosomal RNA genes. J. Eukaryot. Microbiol, v. 46, n. 3, p. 298-301, 1999. https://doi.org/10.1111/j.15507408.1999.tb05128.x. Access en: 13 jul. 2017.

16. DUARTE, Sabrina Castilho et al. Diagnóstico parasitológico e molecular da Babesiose canina na cidade de Goiânia-GO. Rev. patol. trop., v. 37, n. 3, p. 229-236, 2008. https://doi.org/10.5216/rpt.v37i3.5064. Access en: 20 fev. 2020. 
17. YABSLEY, Michael J.; SHOCK, Barbara C. Natural history of zoonotic Babesia: role of wildlife reservoirs. IJP-PAW, v. 2, p. 18-31, 2013. https://doi.org/10.1016/j.ijppaw.2012.11.003. Access en: 18 fev. 2020.

18. FUKUMOTO, Shinya et al. Development of a polymerase chain reaction method for diagnosing Babesia gibsoni infection in dogs. J. Vet. Sci, v. 63, n. 9, p. 977-981, 2001. https://doi.org/10.1292/jvms.63.977. Access en: 22 jul. 2017.

19. IRWIN, Peter J. Canine babesiosis: from molecular taxonomy to control. Parasit Vectors, v. 2, n. 1, p. 1-9, 2009. https://doi.org/10.1186/1756-3305-2-S1-S4. Access en: 25 jul. 2017.

20. BANETH, Gad. Perspectives on canine and feline hepatozoonosis. Vet. Parasitol, v. 181, n. 1, p. 3-11, 2011. https://doi.org/10.1016/j.vetpar.2011.04.015. Access en: 05 jun. 2017.

21. VILELA, J. A. R. et al. Alterações clínico-hematológicas da infecção por Babesia canis vogeli em cães do município de Seropédica, Rio de Janeiro, Brasil. Rev Bras Med Vet, 35(1), 63-68. 2013. Access en: 14 mar. 2017.

22. SOLANO-GALLEGO, G. Baneth. Babesiosis in dogs and cats-expanding parasitological and clinical spectra. Vet. Parasitol, 181, pp. 48 - 60. 2011. https://doi.org/10.1016/j.vetpar.2011.04.023. Access en: 15 jul. 2017.

23. BANETH, Gad. Antiprotozoal treatment of canine babesiosis. Vet. Parasitol, 254: 5863.2018. https://doi.org/10.1016/j.vetpar.2018.03.001. Access en: 10 nov. 2017.

24. OLIVEIRA, MC de S. et al. Fundamentos teóricos-práticos e protocolos de extração e de amplificação de DNA por meio da técnica de reação em cadeia de polimerase. Embrapa Pecuária Sudeste-Livro científico (ALICE), 2007. ISBN:978-85-86764-110. Access en: 11 nov. 2017.

25. MARTIN, Anthony R. et al. Babesia canis vogeli: a novel PCR for its detection in dogs in Australia. Exp. Parasitol., v. 112, n. 1, p. 63-65, 2006. https://doi.org/10.1016/j.exppara.2005.09.001. Access en: 13 set. 2017.

26. KORDICK, Stephanie Kathleen et al. Coinfection with multiple tick-borne pathogens in a Walker Hound kennel in North Carolina. J. Clin. Microbiol, v. 37, n. 8, p. 26312638, 1999. https://doi.org/10.1128/JCM.37.8.2631-2638.1999. Access en: 09 ago. 2017. 
27. DA SILVA, Vanessa Carla Lima et al. Parasitological and molecular detection of Babesia canis vogeli in dogs of Recife, Pernambuco and evaluation of risk factors associated. Semin Cienc Agrar, v. 37, n. 1, p. 163-171, 2016. Access en: 13 mai. 2017.

28. MIRANDA, Farlen Jose Bebber et al. Freqüência de cães infectados por Babesia spp. em Campos dos Goytacazes, RJ. Ciênc. Anim. Bras, v. 9, n. 1, p. 238-241, 2008. Access en: 04 jul. 2017.

29. KJEMTRUP, A. M. et al. There are at least three genetically distinct small piroplasms from dogs. Int. J. Parasitol., v. 30, n. 14, p. 1501-1505, 2000.

https://doi.org/10.1016/S0020-7519(00)00120-X. Access en: 04 jul. 2017.

30. GREENE, Craig E. et al. Infectious diseases of the dog and cat. WB Saunders Vlsevier Science, 2006. ISBN : 072160062X. Access en: 28 mar. 2017.

31. SILVA, Arannadia Barbosa et al. Detecção molecular de Babesia canis vogeli em cães e em Rhipicephalus sanguineus na mesorregião do oeste maranhense, nordeste brasileiro. Ciênc. Anim. Bras, v. 13, n. 3, p. 388-395, 2012. Access en: 04 abr. 2017.

32. FURLANELLO, T. et al. Clinicopathological findings in naturally occurring cases of babesiosis caused by large form Babesia from dogs of northeastern Italy. Vet. Parasitol, v. 134, n. 1-2, p. 77-85, 2005. https://doi.org/10.1016/j.vetpar.2005.07.016. Access en: 14 ago. 2017.

33. HAGIWARA, M. K.; HOLZCHUH, M. P. Infecçao experimental de caes por Babesia canis I Avaliaçao do leucograma durante a evoluçao da doença. Arq. Bras. Med. Vet. Zootec, v. 39, p. 745-755, 1987. Access en: 06 mar. 2018.

34. ZYGNER, W. et al. Biochemical abnormalities observed in serum of dogs infected with large Babesia in Warsaw (Poland). Pol. J. Vet. Sci, v. 10, n. 4, p. 245-253, 2007. PMID: 18198540. Access en: 17 jun. 2017

35. GUIMARÃES, J. C. et al. Aspectos clínico-laboratoriais da babesiose canina na cidade de Campos do Goytacazes, RJ. Rev Bras Parasitol Vet, v. 13, p. 229, 2004. Access en: 13 ago. 2017.

36. GUELFI, J. F. et al. Variations de l'hemogramme en fonction de l'anciennete des symptomes chez les chiens adultes atteints de babesiose aigue spontanee. Rev Med Vet, v. 149, n. 1, p. 65-68, 1998. Access en: 21 ago. 2017. 